\title{
Eating in moderation and the essential role of awareness. A Dutch longitudinal study identifying psychosocial predictors
}

Citation for published version (APA):

Walthouwer, M. J. L., Oenema, A., Candel, M., Lechner, L., \& de Vries, H. (2015). Eating in moderation and the essential role of awareness. A Dutch longitudinal study identifying psychosocial predictors. Appetite, 87, 152-159. https://doi.org/10.1016/j.appet.2014.12.214

Document status and date:

Published: 01/04/2015

DOI:

10.1016/j.appet.2014.12.214

Document Version:

Publisher's PDF, also known as Version of record

Document license:

Taverne

Please check the document version of this publication:

- A submitted manuscript is the version of the article upon submission and before peer-review. There can be important differences between the submitted version and the official published version of record.

People interested in the research are advised to contact the author for the final version of the publication, or visit the DOI to the publisher's website.

- The final author version and the galley proof are versions of the publication after peer review.

- The final published version features the final layout of the paper including the volume, issue and page numbers.

Link to publication

\footnotetext{
General rights rights.

- You may freely distribute the URL identifying the publication in the public portal. please follow below link for the End User Agreement:

www.umlib.nl/taverne-license

Take down policy

If you believe that this document breaches copyright please contact us at:

repository@maastrichtuniversity.nl

providing details and we will investigate your claim.
}

Copyright and moral rights for the publications made accessible in the public portal are retained by the authors and/or other copyright owners and it is a condition of accessing publications that users recognise and abide by the legal requirements associated with these

- Users may download and print one copy of any publication from the public portal for the purpose of private study or research.

- You may not further distribute the material or use it for any profit-making activity or commercial gain

If the publication is distributed under the terms of Article 25fa of the Dutch Copyright Act, indicated by the "Taverne" license above, 
Research report

\section{Eating in moderation and the essential role of awareness. A Dutch longitudinal study identifying psychosocial predictors}

\section{Michel Jean Louis Walthouwer ${ }^{\mathrm{a}, \mathrm{b}, *}$, Anke Oenema ${ }^{\mathrm{a}, \mathrm{b}}$, Math Candel ${ }^{\mathrm{a}, \mathrm{c}}$, Lilian Lechner ${ }^{\mathrm{a}, \mathrm{d}}$, Hein de Vries ${ }^{a, b}$}

a School for Public Health and Primary Care (CAPHRI), Maastricht University, Maastricht, The Netherlands

${ }^{\mathrm{b}}$ Department of Health Promotion, Maastricht University, P.O. Box 616, 6200 MD Maastricht, The Netherlands

' Department of Methodology and Statistics, Maastricht University, P.O. Box 616, 6200 MD Maastricht, The Netherlands

d Department of Psychology, Open University of the Netherlands, P.O. Box 2960, 6419 AT Heerlen, The Netherlands

\section{A R T I C L E I N F O}

\section{Article history:}

Received 5 June 2014

Received in revised form 16 December

2014

Accepted 22 December 2014

Available online 25 December 2014

\section{Keywords:}

Eating in moderation

Awareness

I-Change Model

Determinants

Obesity

\begin{abstract}
A B S T R A C T
Background: Eating in moderation, i.e. the attempt to monitor and limit the intake of energy-dense foods, is a promising strategy in the prevention of weight gain. The purpose of this study was to examine which psychosocial factors derived from the I-Change Model (ICM) were associated with eating in moderation, and whether these factors differed between adults with a correct (aware) or incorrect (unaware) perception of their dietary behaviour. Methods: This study used a longitudinal design with measurements at baseline $(\mathrm{N}=483)$ and six-month follow-up $(\mathrm{N}=379)$. Eating in moderation was defined as the average daily energy intake from energy-dense food products and was measured by a validated food frequency questionnaire. Linear regression analyses were used to assess the associations between the ICM factors and eating in moderation. The moderating role of awareness was examined by including interactions between awareness and the ICM factors in the regression analyses using the pick-a-point approach to further examine the associations for aware and unaware participants. Results: Participants who were aware of their dietary behaviour had a significantly lower average daily energy intake compared to those who were unaware. Eating in moderation was predicted by awareness, risk perception, social influence and intention. Among the aware participants, eating in moderation was predicted by risk perception, attitude, social influence and intention. Among the unaware participants, only risk perception and selfefficacy were significantly associated with eating in moderation. Conclusions: Our findings show that psychosocial factors may only predict eating in moderation when people are aware of their risk behaviour. Therefore, interventions aimed at promoting complex behaviours, such as eating in moderation, should first focus on improving individuals' awareness of their risk behaviour before targeting motivational factors.
\end{abstract}

(C) 2014 Elsevier Ltd. All rights reserved.

\section{Introduction}

In recent decades, the prevalence of overweight and obesity has increased dramatically (World Health Organization, 2013). In 2008, more than 1.4 billion adults worldwide were overweight, and of

\footnotetext{
Role of the funding source: The study was funded by ZonMw, The Netherlands Organization for Health Research and Development (grant number: 200110001). This organization had no role in the study design; in the collection, analysis and interpretation of data; in the writing of the report; and in the decision to submit the article for publication. Conflict of interest: HdV is the scientific director of Vision2Health, a company that licenses evidence-based innovative computer-tailored health communication tools. The other authors declare that they have no competing interests.

* Corresponding author.

E-mail address: michel.walthouwer@maastrichtuniversity.nl (M.J.L. Walthouwer).
}

those, 500 million were obese (World Health Organization, 2013). In the Netherlands in 2012, about $35 \%$ of the adult population was overweight and 13\% were obese (Van den Brink \& Savelkoul, 2013). Overweight and obesity are caused by an imbalance between energy intake and energy expenditure (National Heart Lung and Blood Institute, 2012; Van den Brink \& Savelkoul, 2013). The consumption of energy-dense foods in combination with the increased consumption of large portion sizes of especially energy-dense foods are an important cause of this excessive energy intake (Ello-Martin, Ledikwe, \& Rolls, 2005; Hill, Wyatt, \& Melanson, 2000; Rolls, Roe, \& Meengs, 2007; Steenhuis, Leeuwis, \& Vermeer, 2010; Swinburn, Caterson, Seidell, \& James, 2004). Moreover, several studies have shown that the increase in eating frequency may be an important contributor as well (McCrory, Howarth, Roberts, \& Huang, 2011).

Eating in moderation is the reverse of consuming too much energy-dense food and too many large portions. It can be defined 


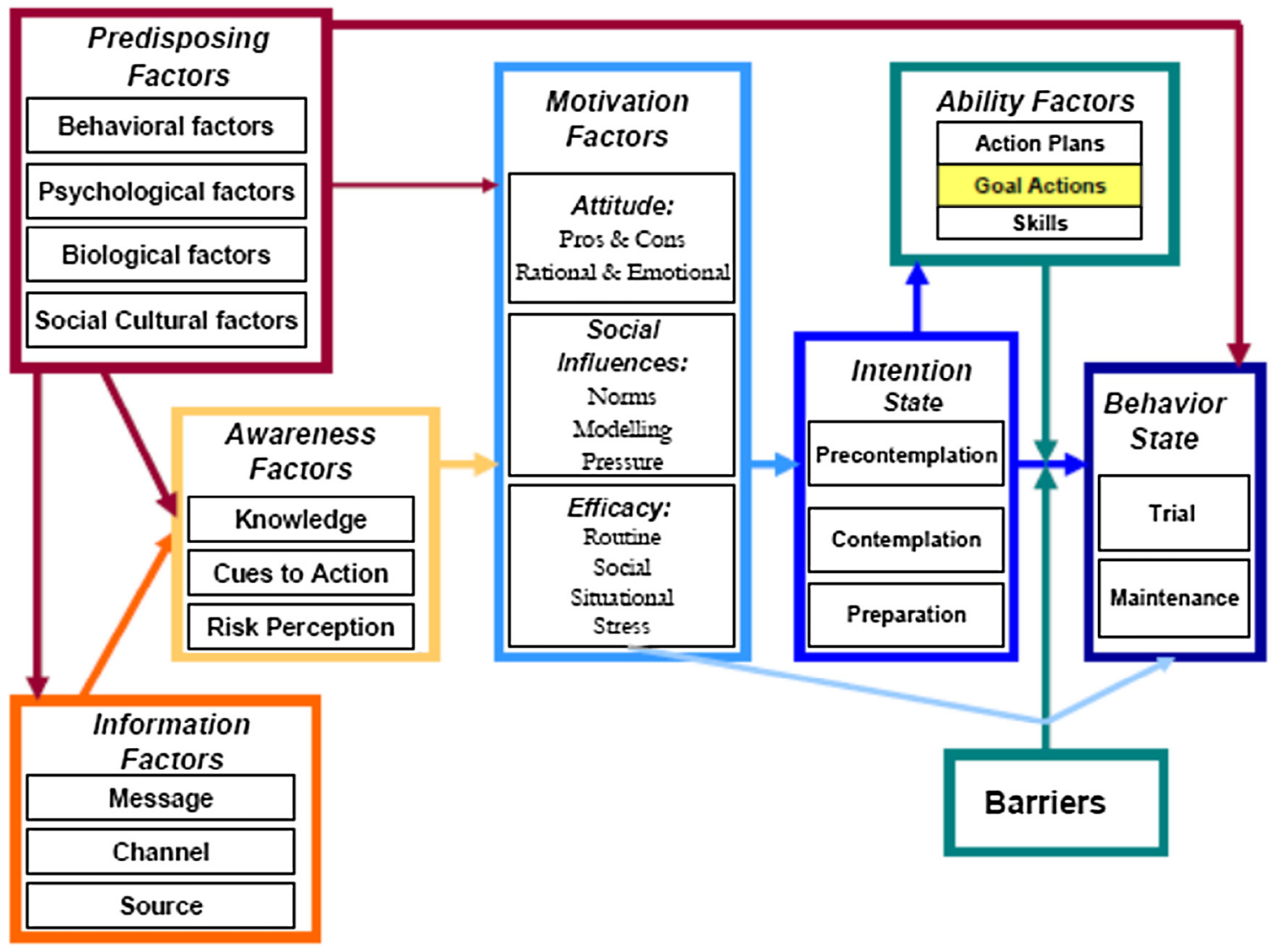

Fig. 1. The I-change model.

as the attempt to monitor and limit the intake of energy-dense foods in order to maintain or achieve a certain body weight (Haines, Siega-Riz, \& Popkin, 1999). This includes, for example, eating small portion sizes, limiting eating frequency and eating lowenergy-dense foods. A positive effect of eating in moderation is that it does not require following a strict diet (Rolls, 2009). Adopting a moderate eating pattern can result in sustained decreases in energy intake without increased feelings of hunger (Kral, Roe, \& Rolls, 2004; Rolls, Roe, \& Meengs, 2006). Hence, to prevent weight gain, adoption of a moderate eating pattern could be a promising strategy to promote in interventions aimed at the prevention of weight gain.

In order to be able to promote eating in moderation through interventions, a clear understanding of the most important determinants of eating in moderation is required (Bartholomew, Parcel, Kok, Gottlieb, \& Fernandez, 2011). However, to date, no studies have been carried out to identify the determinants of this behaviour. Hence, the aim of this study was to identify which psychosocial factors of the I-Change Model (ICM) (de Vries et al., 2003) are associated with eating in moderation. The ICM (see Fig. 1) firstly postulates that various distal factors, such as demographic and biological factors, have an indirect effect on behaviour via sociocognitive variables. The most distal socio-cognitive variables are the pre-motivational factors, including knowledge, cues to action, risk perception (i.e. beliefs about the susceptibility to and severity of developing a certain disease), and awareness of engaging in the risk behaviour (de Vries et al., 2003). These factors subsequently influence various motivational factors such as attitude (pros and cons), self-efficacy, and social influence (modelling, social support, and social norm). These motivational factors together influence an individual's intention to perform a certain health behaviour. Of all these variables, in particular, awareness has been found to be an important factor in the explanation of complex health behaviours such as physical activity and dietary intake (Adams \& White, 2005; Brug et al., 2005; Kloek, van Lenthe, van Nierop, \& Mackenbach, 2004; Ronda, Van Assema, \& Brug, 2001). It has been argued that an adequate awareness of one's own risk behaviour is a precondition for becoming motivated to change complex behaviours (Bogers, Brug, Van Assema, \& Dagnelie, 2004; Brug et al., 2005; Greene et al., 1999; Lechner, Bolman, \& Van Dijke, 2006; Lechner, Brug, De Vries, van Assema, \& Mudde, 1998; Ronda et al., 2001; van Sluijs, Griffin, \& van Poppel, 2007; Weinstein, 1988). People who are aware of their (complex) risk behaviour are more likely to consider change compared to people who are not aware that they are engaging in risk behaviour (Bogers et al., 2004; Brug, van Assema, Kok, Lenderink, \& Glanz, 1994; Lechner et al., 2006; Lechner, Brug, \& De Vries, 1997; Ronda et al., 2001; van Sluijs et al., 2007; Weinstein, 1988). Awareness can thus be considered as a moderating variable within complex behaviours. We hypothesize that awareness of one's own risk behaviour may also be an essential moderating factor for determinants associated with eating in moderation since this is a complex behaviour as well. This would imply that people who incorrectly believe that they eat in moderation may not perceive a need to change and accordingly have no motivation to change their behaviour. Correspondingly, we expect that the motivational factors of the ICM do not predict eating in moderation among respondents who are unaware of their behaviour.

To examine this hypothesis, the aim of this study was to assess which psychosocial factors of the ICM are associated with eating in moderation and whether these factors differ between Dutch adults with a correct (aware) or incorrect (unaware) perception of their dietary behaviour. 
Table 1

Overview of number and examples of questions, answering categories, mean scores and Cronbach's alphas.

\begin{tabular}{|c|c|c|c|c|}
\hline Concept & Number of questions & Examples of questions, answering options, and range & Mean (SD) & Cronbach's alpha \\
\hline \multicolumn{5}{|l|}{ Behaviour } \\
\hline $\begin{array}{l}\text { Eating in moderation (i.e. } \\
\text { average daily energy intake } \\
\text { from energy-dense food } \\
\text { products) }\end{array}$ & 66 & $\begin{array}{l}\text { - Frequency: On how many days do you generally eat/drink } \\
\text { product x }{ }^{\mathrm{d}} \\
\text { - Quantity: On a day you eat/drink product x, how much do you } \\
\text { consume on average on a single day }{ }^{\mathrm{d}} \\
\text { - Portion size: On a day you eat/drink product x, how many } \\
\text { grams do you consume on average each time? } \\
\text { - Type of product: On a day you eat/drink product } \mathrm{x} \text {, what kind } \\
\text { of product do you usually consume? }\end{array}$ & $906.0(393.3)^{b}$ & - \\
\hline Dairy products & 13 & $\begin{array}{l}\text { Products: milk, chocolate milk, yogurt, sugar-sweetened dairy } \\
\text { beverages, pudding }\end{array}$ & $108.2(87.8)^{\mathrm{b}}$ & - \\
\hline Sandwiches and fillings & 13 & Products: bread, cheese, meat, chocolate spread, butter & $247.4(162.4)^{b}$ & - \\
\hline Food eaten during dinner & 10 & Products: sausage, minced meat, bacon, cheese, gravy & $95.7(77.4)^{\mathrm{b}}$ & - \\
\hline Sweet and savoury snacks & 21 & $\begin{array}{l}\text { Products: fried snacks, peanuts, potato chips, cheese, cake, } \\
\text { chocolate, candy bars, biscuits, cookies }\end{array}$ & $262.0(214.2)^{\mathrm{b}}$ & - \\
\hline Hot and cold beverages & 5 & Products: coffee, tea, sugar-sweetened drinks & $140.8(146.9)^{\mathrm{b}}$ & - \\
\hline Alcohol & 4 & Products: beer, wine, spirits & $83.9(117.5)^{\mathrm{b}}$ & - \\
\hline \multicolumn{5}{|l|}{ Determinants } \\
\hline $\begin{array}{l}\text { Awareness of eating in } \\
\text { moderation }^{\mathrm{a}}\end{array}$ & 1 & I usually: Never eat in moderation (1)-always eat in moderation (5) & - & - \\
\hline $\begin{array}{l}\text { Risk perception: } \\
\text { susceptibility }\end{array}$ & 5 & $\begin{array}{l}\text { If I do not eat in moderation, my body weight will rise. } \\
\text { Completely disagree (1)-completely agree (5) }\end{array}$ & $3.7(0.6)^{c}$ & 0.81 \\
\hline Risk perception: severity & 7 & Gaining weight is: Not serious at all (1)-very serious (5) & $3.3(0.6)^{c}$ & 0.83 \\
\hline Attitude: pros & 10 & $\begin{array}{l}\text { If I eat in moderation, my health will improve. } \\
\text { Completely disagree (1)-completely agree (5) }\end{array}$ & $3.8(0.5)^{\mathrm{c}}$ & 0.94 \\
\hline Attitude: cons & 10 & $\begin{array}{l}\text { If I eat in moderation, I cannot eat everything I want to eat. } \\
\text { Completely disagree (1)-completely agree (5) }\end{array}$ & $2.6(0.6)^{c}$ & 0.91 \\
\hline $\begin{array}{l}\text { Social influence: subjective } \\
\text { norm }\end{array}$ & 4 & $\begin{array}{l}\text { Most people who are important to me, think eating in moderation } \\
\text { is important. Completely disagree (1)-completely agree (5) }\end{array}$ & $3.0(0.7)^{c}$ & 0.73 \\
\hline Social influence: modelling & 3 & $\begin{array}{l}\text { Most people who are important to me, eat in moderation. } \\
\text { Completely disagree (1)-completely agree (5) }\end{array}$ & $3.3(0.9)^{c}$ & 0.88 \\
\hline $\begin{array}{l}\text { Social influence: social } \\
\text { support }\end{array}$ & 6 & $\begin{array}{l}\text { Most people who are important to me, encourage me to eat in } \\
\text { moderation. Completely disagree (1)-completely agree (5) }\end{array}$ & $2.6(0.6)^{c}$ & 0.85 \\
\hline Self-efficacy & 2 & $\begin{array}{l}\text { I find it: Very difficult to eat in moderation (1)-very easy to eat in } \\
\text { moderation (5) }\end{array}$ & $3.0(0.9)^{c}$ & - \\
\hline Intention & 1 & $\begin{array}{l}\text { Do you intend to eat in moderation within the next six months? } \\
\text { Certainly not (1)-certainly (5) }\end{array}$ & $3.9(1.3)^{c}$ & - \\
\hline
\end{tabular}

a This factor was computed in combination with individuals' reported average daily energy intake.

b Average daily energy intake in kilocalories.

c Mean score on five-point Likert scale.

d In the questionnaire, 'product x' was replaced by the food products of the different food categories.

\section{Materials and methods}

\section{Study design and participants}

This study used a longitudinal design with a baseline measurement (T0) and a six-month follow-up measurement (T1). Based on a power calculation suggested by Tabachnick and Fidell (2001), we needed to recruit at least 300 participants. For this purpose, members of an Internet research panel (Flycatcher, the Netherlands) were invited to participate in the study and to complete an online questionnaire. At baseline, 942 members of the online panel were approached, of which 483 participated (response $=51 \%$ ) and 379 completed the follow-up questionnaire (response $=78 \%$ of those who started). Individuals were eligible to participate when they (a) were between 18 and 65 years old, (b) had a job, (c) had access to the Internet and (d) were a member of the online panel.

\section{Questionnaire}

\section{Eating in moderation}

Eating in moderation was defined as the average daily intake of energy from energy-dense food products. A low score means that a participant eats in moderation, whereas a high score indicates that a participant is not eating in moderation. The average daily intake of energy-dense food products was assessed by means of a food frequency questionnaire consisting of 66 items, which was based on a validated questionnaire to assess fat intake (Van Assema, Brug, Ronda, \& Steenhuis, 2001) and expanded with additional food categories (e.g. alcohol and sugar-sweetened beverages) in order to measure the intake of energy-dense food products that are common in the Dutch diet. The following food categories were included: dairy products, sandwiches and fillings, food eaten during dinner, sweet and savoury snacks, hot and cold beverages and alcohol. A high intake of foods from these categories has been associated with weight gain (Mozaffarian, Hao, Rimm, Willett, \& Hu, 2011; Newby et al., 2003). For each food product, the frequency, i.e. 'On how many days do you generally eat/drink product $x$ ?', and quantity, i.e. 'On a day you eat/ drink product $\mathrm{x}$, how much do you consume on average on a single day?', were assessed. For some food products, e.g. meat consumption, the portion size was assessed as well, i.e. 'On a day you eat/ drink product $\mathrm{x}$, how many grams do you consume on average each time?' For some of the products, such as dairy, the type of product (low, medium or high fat) was also measured. A score for the average daily intake of the energy-dense products was calculated by multiplying the energy value of each product by the frequency and the quantity in which each food product was consumed. Further, we also made a dichotomous variable of eating in moderation using a median split. A score below the median was coded as eating in moderation, while a score above the median was coded as not eating in moderation. A complete overview of the measured food products, examples of questions and mean scores can be found in Table 1. 
Psychosocial determinants of eating in moderation

The ICM was used as framework for including determinants concerning eating in moderation in the questionnaire. These determinants were only measured at baseline, with a total of 49 questions. All answering categories of the psychosocial variables consisted of a five-point Likert scale, ranging from 1 (= low) to 5 (= high). For each determinant except awareness, a scale was computed by calculating a mean score of all corresponding questions. The questionnaire also consisted of several explorative concepts which were not used for the present study, including anticipated regret, response efficacy, planning, and process evaluation questions about the questionnaire. Details on the assessed determinants, including number and examples of questions per determinant, answer categories, mean scores and Cronbach's alphas, are presented in Table 1.

Awareness of eating in moderation was assessed by combining the dichotomous variable of eating in moderation with self-perceived eating in moderation. To assess the participants' own perceptions of eating in moderation, they were asked if they thought that they usually ate in moderation, i.e. 'I usually (never - always) eat in moderation'. This variable was dichotomized to 0 for not or not always eating in moderation and 1 for always eating in moderation. By combining this variable with the dichotomous variable concerning eating in moderation, four groups of participants could be distinguished: (1) participants who correctly indicated that they usually ate in moderation (aware); (2) participants who correctly indicated that they usually did not eat in moderation (aware); (3) participants who incorrectly indicated that they usually ate in moderation (unaware); and (4) participants who incorrectly indicated that they usually did not eat in moderation (unaware). For the analyses, these four groups were combined into a dichotomous variable, distinguishing between participants who were aware of their dietary behaviour and participants who were unaware of their actual dietary behaviour. ${ }^{1}$

Risk perception was measured using seven questions for perceived severity, e.g. gaining weight is (not serious at all - very serious), and five questions for perceived susceptibility, e.g. 'If I do not eat in moderation, my body weight will rise'.

Participants' attitude toward eating in moderation was assessed by asking about their perception of ten pros, e.g. improved fitness, beneficial for health, maintaining weight, and ten cons, e.g. unhealthy, hunger, spoiling food. Social influence was measured with four questions for subjective norm, e.g. 'Most people who are important to me, think that eating in moderation is important', three questions for modelling, e.g. 'Most people who are important to me, eat in moderation', and six questions for social support, e.g. 'Most people who are important to me, encourage me to eat in moderation'. Self-efficacy was measured by two questions concerning the perceived difficulty to eat in moderation, e.g. 'I find it (very difficult - very easy) to eat in moderation'.

Finally, the participants' intention to eat in moderation was assessed by one question, i.e. 'Do you intend to eat in moderation within the next six months?'

\section{Demographics}

The baseline questionnaire also assessed several self-reported demographic characteristics, including gender, age, educational level, household composition as well as height and body weight to calculate body mass index (BMI). Educational level, i.e. the highest level of education completed, was recoded into three categories: low (primary or basic vocational school), medium (secondary voca-

\footnotetext{
1 Analyses with the four individual awareness groups were prohibited because of a too low power.
}

tional school or high school) and high (higher vocational school or university) (Verweij, 2013). Household composition was dichotomized into living alone versus living together.

\section{Statistical analyses}

All statistical analyses were conducted using SPSS 19.0, applying a significance level of 0.05 for two-tailed tests. Descriptive statistics and frequencies were used to describe the study population. A logistic regression analysis was performed to examine possible selective attrition of participants between baseline and follow-up regarding demographics. Descriptive statistics, independent samples t-tests and crosstab analyses were performed to describe the aware and unaware groups and to examine differences in demographic characteristics between these two subgroups. To identify determinants of eating in moderation, multiple linear regression analysis was performed by regressing the variables of the ICM on eating in moderation. To examine if level of awareness moderated the associations between the ICM variables and eating in moderation, interactions between awareness and ICM variables were included, which were further examined using the pick-a-point approach of Hayes and Matthes (2009) for probing interactions. The latter was done by performing two separate regression analyses with interaction terms between awareness and the ICM variables in the model and using a different reference category for awareness. In one analysis, awareness was categorized as 1 , while unawareness was categorized as 0 . In the second analysis, awareness was categorized as 0 and unawareness as 1 . By changing the coding, we were able to further examine the interaction terms with the full sample and get separate regression coefficients for each of the determinants according to the ICM for both awareness levels. In all regression analyses, the independent variables were entered in five consecutive steps as required by the theoretical model (ICM) that underpinned our study: (1) demographic factors, (2) pre-motivational factors, (3) motivational factors, (4) intention and (5) eating in moderation measured at baseline, which was entered as a last step to examine its additional value.

\section{Results}

\section{Participants}

The study population consisted of 204 men (53.8\%) and 175 women $(46.2 \%)$. The mean age was 44.0 years $(S D=13.5)$ and a majority of the participants (82.8\%) were living together with a partner, spouse or child. Further, $29.0 \%$ of the participants had a low level of education, $38.3 \%$ had a medium educational level and $32.7 \%$ had a high level of education. The mean BMI was $26.7(\mathrm{SD}=5.0)$ and $19.8 \%$ were obese, $39.8 \%$ were overweight and $40.4 \%$ had a healthy weight. The attrition analysis showed that participants with a low BMI were more likely to drop-out than those with a higher BMI $(\mathrm{OR}=0.93,95 \% \mathrm{CI}=0.88-0.98, \mathrm{p}<0.05)$.

\section{Eating in moderation}

The average daily intake of the energy-dense food products was 946.4 kilocalories ( $\mathrm{kcal}$ ) at baseline $(\mathrm{SD}=413.3$, range $=170.3-$ 2272.3 ) and $906.0 \mathrm{kcal}$ at six-month follow-up (SD = 393.3, range $=110.1-2175.1$ ). The categories of sweet and savoury snacks, sandwiches and fillings and hot and cold beverages were the most important sources for high energy intake. Dairy products, food at dinner and alcohol contributed the least to the energy intake from energy-dense foods (see Table 1 ). 
Table 2

Differences in demographics between aware and unaware participants.

\begin{tabular}{lccc}
\hline & N Aware (\%) & N Unaware (\%) & Pearson's $\chi^{2}$ \\
\hline Gender & & & .21 \\
Men & $103(27.2)$ & $101(26.6)$ & \\
Women & $93(24.6)$ & $82(21.6)$ & 2.99 \\
Age & $56(14.8)$ & $67(17.7)$ & \\
$18-36$ & $67(17.7)$ & $54(14.1)$ & \\
$37-50$ & $73(19.3)$ & $62(16.4)$ & 5.72 \\
$51-66$ & & & \\
BMI & $76(20.1)$ & $77(20.4)$ & .80 \\
Healthy weight & $81(21.4)$ & $70(18.3)$ & \\
Overweight & $39(10.3)$ & $36(9.5)$ & \\
Obese & & & \\
Educational level & $58(15.3)$ & $51(13.5)$ & \\
Low & $71(18.8)$ & $74(19.6)$ & \\
Middle & $67(17.7)$ & $58(15.1)$ & \\
High & & & \\
Household composition & $162(42.9)$ & $152(39.9)$ & \\
Together & $34(9.0)$ & $31(8.2)$ & \\
Alone &
\end{tabular}

\section{Awareness of eating in moderation}

About half of the study population (51.9\%) were categorized as correctly aware of whether or not they eat in moderation, while $48.1 \%$ were considered to have a wrong perception, i.e. were unaware. Of the aware participants, the majority correctly indicated that they usually ate in moderation (68.0\%), while $32.0 \%$ correctly indicated that they usually did not eat in moderation. Of the unaware participants, $75.3 \%$ incorrectly thought that they usually ate in moderation, while $24.7 \%$ incorrectly indicated that they usually did not eat in moderation. Participants who were aware of their intake had a significantly $(\mathrm{t}=-3.68, \mathrm{p}<0.01)$ lower average daily energy intake (mean $=835.1, \mathrm{SD}=404.1$ ) than the unaware participants (mean $=983.4, \mathrm{SD}=367.9$ ). Table 2 further shows that there were no significant differences in demographics between the aware and unaware participants.

\section{Correlations between demographics, ICM variables, and eating in moderation}

The Pearson's correlations between the demographic variables, ICM variables, and eating in moderation are shown in Table 3. All demographic variables had a significant negative correlation with baseline eating in moderation. At follow-up, age was the only demographic variable that was not significantly correlated with eating in moderation. Further, being aware of one's own dietary behaviour was significantly correlated with a high level of eating in moderation at both baseline as follow-up. Having a high perceived severity and perceived susceptibility correlated significantly with a high level of eating in moderation at baseline and follow-up. Of the motivational factors, attitude pro, subjective norm, and social support correlated significantly with eating in moderation at both baseline and follow-up. Intention correlated with nearly all motivational variables and having a high intention was significantly associated with a high level of eating in moderation at baseline and follow-up.

\section{Determinants of eating in moderation}

Table 4 shows the results of the multiple linear regression analyses. Note that a lower average daily energy implies a higher level of eating in moderation and vice versa. A negative association in the regression analysis thus implies a relationship as expected, i.e. a positive finding.

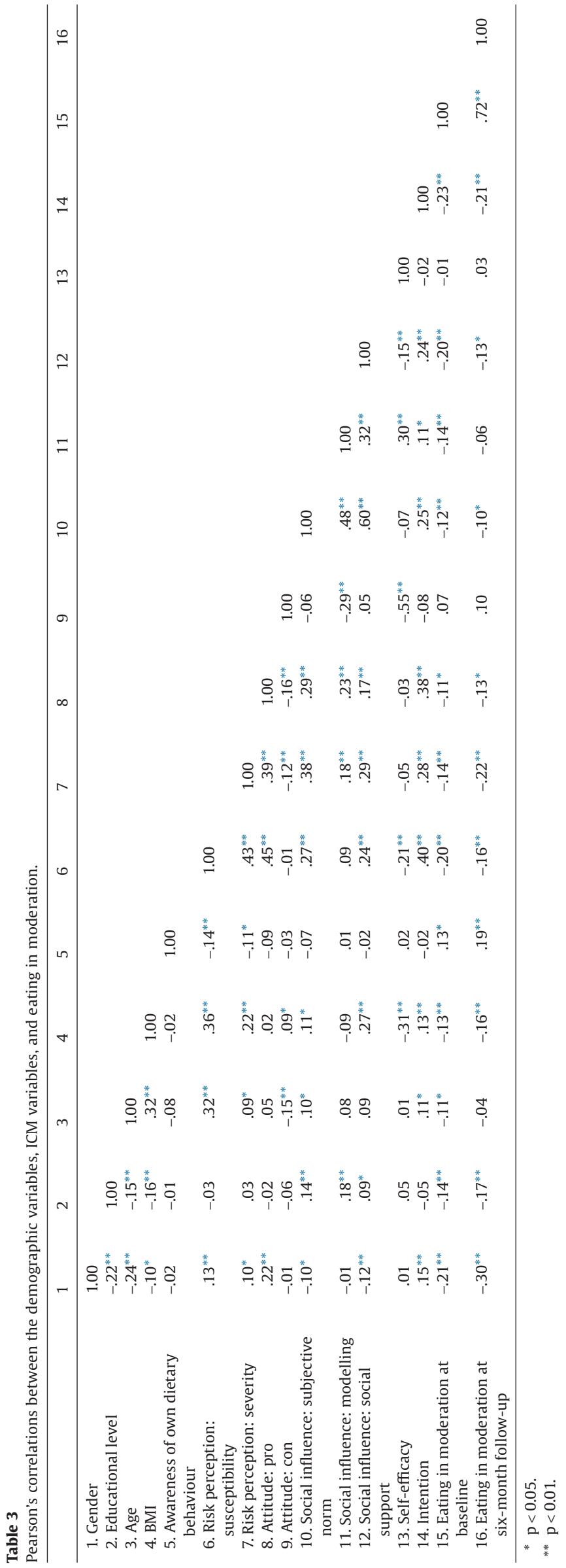




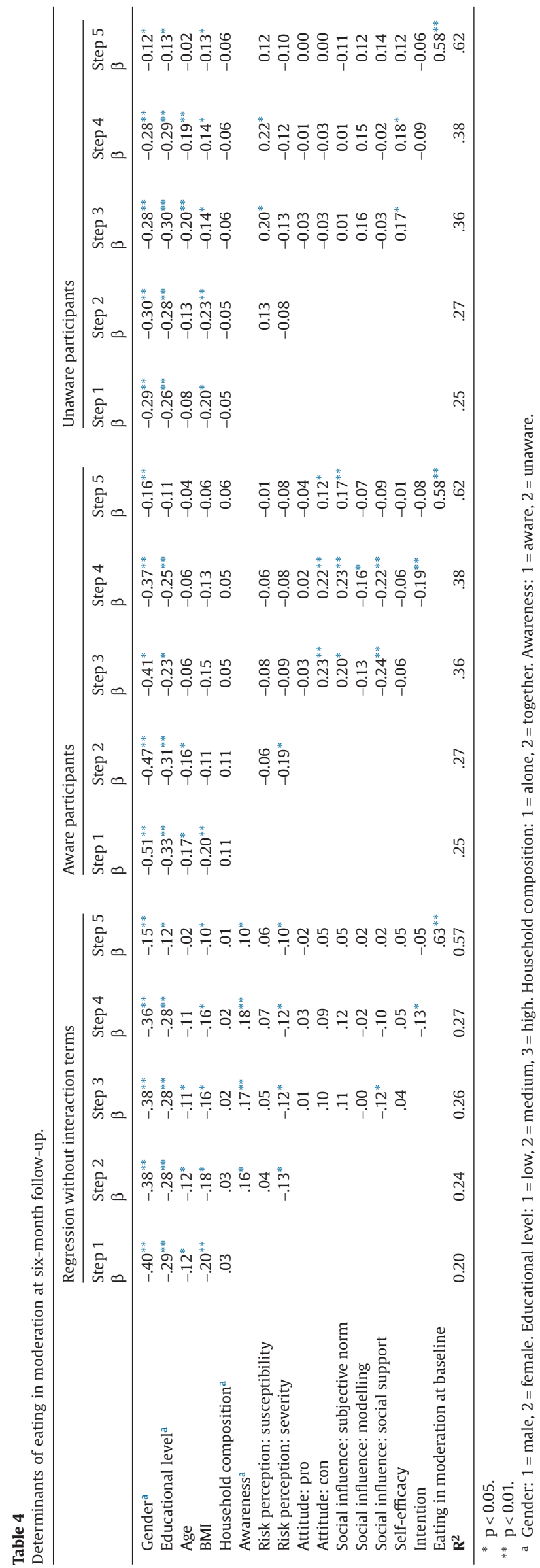

Results from the regression analysis with only main effects demonstrate that in step 1 the level of eating in moderation was significantly higher among female participants, participants with a high level of education, older participants and participants with a high BMI. Results from step 2 show that aware participants and those with a high perceived severity were significantly more likely to eat in moderation. In step 3, these variables remained significant, while social support was found to be the only significant motivational factor. After adding intention in step 4, the significant association of social support disappeared while awareness and perceived severity remained significant predictors. Participants with a high intention to eat in moderation were also significantly more likely to eat in moderation. In the final model, the significant association of intention disappeared, while baseline behaviour significantly predicted eating in moderation at follow-up. The explained variance increased from $27 \%$ to $57 \%$ in this last step.

We subsequently performed regression analyses with interaction terms between the dichotomous awareness variable and the ICM variables to examine the moderating role of awareness. Using the pick-a-point approach we examined the associations for aware and unaware participants by switching the $0-1$ coding for the awareness variable. As can be seen in Table 4, among the participants who were aware of their dietary intake, results from step 1 demonstrate that the level of eating in moderation was significantly higher among female participants, participants with a high level of education, older participants and participants with a high BMI. Results from step 2 show that participants with a high perceived severity were more likely to eat in moderation. The significant association of BMI disappeared in this step. In step 3, the significant association of perceived severity disappeared, while the level of eating in moderation was significantly higher among participants who perceived few cons, a lot of social support and a negative subjective norm toward eating in moderation. In step 4, all previous associations remained significant while modelling and intention also became significant predictors. After adding baseline behaviour in step 5, several significant associations disappeared.

Among the unaware participants (see Table 4), the level of eating in moderation was significantly higher among female participants, participants with a high level of education and participants with a high BMI in step 1 . The results from step 2 show no additional or disappearing significant associations. In step 3, perceived susceptibility and age became significant predictors. Of the motivational factors, only self-efficacy had a significant association with eating in moderation. Remarkably, participants with a high selfefficacy were less likely to eat in moderation. The results of step 4 were identical to step 3 . In the last step, the significant associations of self-efficacy, perceived susceptibility and age disappeared, while baseline behaviour significantly predicted eating in moderation at follow-up.

\section{Discussion}

The purpose of this study was to examine which factors of the ICM were associated with eating in moderation and whether there was a difference in these factors between Dutch adults who were aware of their dietary behaviour and those who were unaware.

In line with other studies on complex health-related behaviours (Bogers et al., 2004; Brug et al., 1994; Glanz, Brug, \& Van Assema, 1997; Lechner et al., 1997, 1998, 2006; Ronda et al., 2001; van Sluijs et al., 2007), our study shows that half of the participants were unaware of whether or not they eat in moderation and that the majority of these people had an optimistic bias, i.e. they thought to eat in moderation while they did not. In line with the expectations, awareness of dietary behaviour was found to be an important factor in the explanation of eating in moderation, since it was a moderator of the association between the ICM variables and behaviour 
(Bogers et al., 2004; Brug et al., 1994; Kloek et al., 2004; Lechner et al., 1997; van Sluijs et al., 2007). The regression analyses with interaction terms showed that only when participants had a correct perception of whether or not they ate in moderation, motivational factors such as attitude, social influence and intention were significantly associated with eating in moderation.

The finding that motivational factors were not predictive of behaviour when people were unaware of their behaviour is in line with the findings of previous studies (Bogers et al., 2004; Brug et al., 1994; Kloek et al., 2004; Lechner et al., 1997; van Sluijs et al., 2007). Without an adequate awareness of one's own risk behaviour, these unaware people will not perceive a need to change and, accordingly, will have no motivation to change (Bogers et al., 2004; Brug et al., 1994; Lechner et al., 1997, 2006; Ronda et al., 2001; van Sluijs et al., 2007; Weinstein, 1988). Further, unaware people could, in principle, be highly motivated to eat in moderation and can have a positive attitude. However, these factors are not very likely to predict behaviour in this subgroup since they think that they already perform the desired behaviour. Lack of awareness can thus act as a barrier in the process of behaviour change and limit the effectiveness of interventions aimed to promote eating in moderation (Ronda et al., 2001).

In contrast to these results, the motivational factors were significantly associated with eating in moderation among participants who were aware of their dietary behaviour. This implies that people should first be aware of their behaviour, before motivational factors become of importance. This is supported by the fact that the explained variance was much higher in the aware group after adding the motivational factors compared to the unaware group. This finding is supported by previous research (Bogers et al., 2004; van Sluijs et al., 2007), which suggests that the predictive value of sociocognitive theories is higher among people who are aware of their risk behaviour. It should, however, be noted that in line with many reviews (Hagger, Chatzisarantis, \& Biddle, 2002; Kidwell \& Jewell, 2008; Sutton, 1994; Trost, Owen, Bauman, Sallis, \& Brown, 2002), baseline behaviour was the strongest predictor of eating in moderation. However, it still is important to target the psychosocial cognitions, because by adding past behaviour, behaviour change is taken into account.

It is important to recognize that awareness plays an essential role in eating in moderation as this calls for tailored intervention strategies for people who are unaware of their risk behaviour (Brug et al., 1994; Lechner et al., 2006; Ronda et al., 2001). Based on our findings, we recommend that future interventions aimed at promoting eating in moderation first aim to achieve an adequate awareness level before targeting motivational factors. Giving feedback on behaviour is an effective technique that can be used to create awareness (Bartholomew et al., 2011; Michie et al., 2011; Weinstein, 1988). It has been suggested that this can be done efficiently using webbased computer-tailored interventions, as these can raise people's awareness relatively easily by providing individualized feedback about their behaviour (Oenema \& Brug, 2003).

Our findings were not completely in line with our hypothesis, since two significant associations were not in the expected direction among the unaware participants. The finding that having a high risk perception was associated with a lower level of eating in moderation can, however, be explained by the fact that these individuals were unaware of their dietary behaviour and most of them incorrectly thought that they ate in moderation. As suggested by a review about factors affecting food choice (Pollard, Kirk, \& Cade, 2002), these unaware participants probably had an optimistic bias and consequently may have thought that they were less at risk (Weinstein \& Lyon, 1999). The finding that a high self-efficacy for eating in moderation was associated with a lower level of eating in moderation can also be related to this optimistic bias (Pollard et al., 2002; Weinstein \& Lyon, 1999). The largest part of the unaware partici- pants thought that they already performed the desired behaviour and they may have experienced that this behaviour was relatively easy to achieve, which may be reflected in a high self-efficacy. However, in this case self-efficacy is not related to actual eating in moderation.

The finding that there was no significant relationship between self-efficacy and eating in moderation among the aware participants may be explained by the manner in which self-efficacy was measured. Thinking that something is easy to do does not necessarily mean that one is able to perform the behaviour successfully. Another remarkable finding among the aware participants was that the level of eating in moderation was lower among participants who indicated that important others thought that they should eat in moderation, i.e. subjective norm. This finding can, however, be explained by the presence of a suppressor effect (Lancaster, 1999), i.e. when the univariate association between two variables disappears or even turns around when adding other variables. Our results show that this happened for subjective norm, since a Pearson correlation analysis showed that the level of eating in moderation was significantly higher among participants who perceived a positive norm toward eating in moderation $(\mathrm{r}=.10, \mathrm{p}<0.05)$, while this relation was reversed in the regression analysis.

The results of this study should be interpreted in the light of three important limitations. The use of the median split to classify the daily energy intake into eating in moderation versus not eating in moderation was somewhat arbitrary. We have, however, three good reasons for using this procedure. First, about $50 \%$ of Dutch adults have an energy intake higher than the daily recommended energy intake (van Rossum, Fransen, Verkaik-Kloosterman, Buurma-Rethans, \& Ocké, 2011); therefore, we expected to have the same distribution in our sample. Second, the median split was made separately for men and women, as men are allowed to have a higher daily energy intake than women. Third, we also verified this approach using a more conservative approach in which we classified the average daily energy intake of the lowest $67 \%$ into eating in moderation and the top 33\% into not eating in moderation. Performing the analyses using these cut-off points resulted in findings in the same direction. Another aspect to mention is the dichotomous classification of awareness, through which both awareness subgroups consisted of people who did and who did not eat in moderation. The subgroup of aware participants, for example, included both participants who correctly indicated that they usually ate in moderation as well as participants who were correctly aware of the fact that they did not eat in moderation. We did, however, also perform separate regression analyses for the four awareness subgroups. The results of these analyses did not demonstrate obvious differences between these groups. This implies that being aware is important in itself, regardless of whether this is the (un)awareness of eating in moderation or not eating in moderation. Furthermore, the use of the average daily energy intake as an indicator for eating in moderation can be considered as suboptimal. However, eating in moderation is a complex behaviour which could be measured in many different ways. Currently, it is unknown what the best indicator for this behaviour is and, eventually, everything comes down to the energy intake. We further also measured all aspects of eating in moderation in our questionnaire, such as the frequency, quantity, portion size and type of product. Finally, it should be noted that this is the first study that has identified the determinants of eating in moderation and examined the moderating role of awareness for this behaviour. Further research on this behaviour is recommended in order to replicate our findings.

\section{Conclusions}

The aim of this study was to identify determinants of eating in moderation and to study differential effects based on people's level 
of awareness in order to be able to target the most important determinants in interventions aimed at preventing overweight and obesity. This study shows that awareness of one's own risk behaviour is a key factor in eating in moderation. Misperception of one's own risk behaviour may act as a barrier when promoting eating in moderation as unaware people will not perceive a need to change and have no motivation to change. This can limit the efficacy of interventions that only focus on motivational factors. Hence, interventions aimed at promoting eating in moderation should first focus on achieving an adequate awareness level of one's own dietary behaviour before targeting motivational factors, such as attitude, social influence and intention. By following this sequence, the adoption of a moderate eating pattern can be promoted effectively in, for example, web-based computer-tailored interventions.

\section{References}

Adams, J., \& White, M. (2005). Why don't stage-based activity promotion interventions work? Health Education Research, 20(2), 237-243.

Bartholomew, L. K., Parcel, G. S., Kok, G., Gottlieb, N. H., \& Fernandez, M. E. (2011). Planning health promotion programs. An intervention mapping approach (3rd ed.). San Francisco: Jossey-Bass.

Bogers, R., Brug, J., Van Assema, P., \& Dagnelie, P. (2004). Explaining fruit and vegetable consumption. The Theory of Planned Behaviour and misconception of personal intake levels. Appetite, 42(2), 157-166.

Brug, J., Conner, M., Harré, N., Kremers, S., McKellar, S., \& Whitelaw, S. (2005). The Transtheoretical Model and stages of change. A critique observations by five commentators on the paper by Adams, J. and White, M. (2004) Why don't stage-based activity promotion interventions work? Health Education Research, 20(2), 244-258.

Brug, J., van Assema, P., Kok, G., Lenderink, T., \& Glanz, K. (1994). Self-rated dietary fat intake. Association with objective assessment of fat, psychosocial factors, and intention to change. Journal of Nutrition Education, 26(5), 218-223.

de Vries, H., Mudde, A., Leijs, I., Charlton, A., Vartiainen, E., Buijs, G., et al. (2003). The European Smoking Prevention Framework Approach (EFSA). An example of integral prevention. Health Education Research, 18(5), 611-626.

Ello-Martin, J. A., Ledikwe, J. H., \& Rolls, B. J. (2005). The influence of food portion size and energy density on energy intake. Implications for weight management. The American Journal of Clinical Nutrition, 82(1), 236-241.

Glanz, K., Brug, J., \& Van Assema, P. (1997). Are awareness of dietary fat intake and actual fat consumption associated? A Dutch-American comparison. European Journal of Clinical Nutrition, 51(8), 542-547.

Greene, G. W., Rossi, S. R., Rossi, J. S., Velicer, W. F., Fava, J. L., \& Prochaska, J. O. (1999). Dietary applications of the stages of change model. Journal of the American Dietetic Association, 99(6), 673-678.

Hagger, M. S., Chatzisarantis, N. L., \& Biddle, S. J. (2002). A meta-analytic review of the theories of reasoned action and planned behavior in physical activity. Predictive validity and the contribution of additional variables. Journal of Sport E Exercise Psychology.

Haines, P. S., Siega-Riz, A. M., \& Popkin, B. M. (1999). The Diet Quality Index revised. A measurement instrument for populations. Journal of the American Dietetic Association, 99(6), 697-704.

Hayes, A. F., \& Matthes, J. (2009). Computational procedures for probing interactions in OLS and logistic regression. SPSS and SAS implementations. Behavior Research Methods, 41(3), 924-936.

Hill, J. O., Wyatt, H. R., \& Melanson, E. L. (2000). Genetic and environmental contributions to obesity. Medical Clinics of North America, 84(2), 333-346.

Kidwell, B., \& Jewell, R. D. (2008). The influence of past behavior on behavioral intent. An information-processing explanation. Psychology \& Marketing, 25(12), 1151 1166.

Kloek, G. C., van Lenthe, F. J., van Nierop, P. W., \& Mackenbach, J. P. (2004). Stages of change for fruit and vegetable consumption in deprived neighborhoods. Health Education \& Behavior, 31(2), 223-241.

Kral, T. V., Roe, L. S., \& Rolls, B. J. (2004). Combined effects of energy density and portion size on energy intake in women. The American Journal of Clinical Nutrition, 79(6), 962-968.

Lancaster, B. P. (1999). Defining and interpreting suppressor effects. Advantages and limitations. In B. Thompson (Ed.), Advances in social science methodology (pp. 139-148). Stanford, CT: JAI Press.

Lechner, L., Bolman, C., \& Van Dijke, M. (2006). Factors related to misperception of physical activity in The Netherlands and implications for health promotion programmes. Health Promotion International, 21(2), 104-112.
Lechner, L., Brug, J., \& De Vries, H. (1997). Misconceptions of fruit and vegetable consumption. Differences between objective and subjective estimation of intake. Journal of Nutrition Education, 29(6), 313-320.

Lechner, L., Brug, J., De Vries, H., van Assema, P., \& Mudde, A. (1998). Stages of change for fruit, vegetable and fat intake. Consequences of misconception. Health Education Research, 13(1), 1-11.

McCrory, M. A., Howarth, N. C., Roberts, S. B., \& Huang, T. T.-K. (2011). Eating frequency and energy regulation in free-living adults consuming self-selected diets. The Journal of Nutrition, 141(1), 148-153.

Michie, S., Ashford, S., Sniehotta, F. F., Dombrowski, S. U., Bishop, A., \& French, D. P. (2011). A refined taxonomy of behaviour change techniques to help people change their physical activity and healthy eating behaviours. The CALO-RE taxonomy. Psychology \& Health, 26(11), 1479-1498.

Mozaffarian, D., Hao, T., Rimm, E. B., Willett, W. C., \& Hu, F. B. (2011). Changes in diet and lifestyle and long-term weight gain in women and men. New England Journal of Medicine, 364(25), 2392-2404.

National Heart Lung and Blood Institute. (2012). What causes overweight and obesity? <http://www.nhlbi.nih.gov/health/health-topics/topics/obe/causes.html>. Last accessed 14.06.

Newby, P., Muller, D., Hallfrisch, J., Qiao, N., Andres, R., \& Tucker, K. L. (2003). Dietary patterns and changes in body mass index and waist circumference in adults. The American Journal of Clinical Nutrition, 77(6), 1417-1425.

Oenema, A., \& Brug, J. (2003). Feedback strategies to raise awareness of personal dietary intake. Results of a randomized controlled trial. Preventive Medicine, 36(4), 429-439.

Pollard, J., Kirk, S., \& Cade, J. (2002). Factors affecting food choice in relation to fruit and vegetable intake. A review. Nutrition Research Reviews, 15(2), 373-388.

Rolls, B. J. (2009). The relationship between dietary energy density and energy intake. Physiology \& Behavior, 97(5), 609-615.

Rolls, B. J., Roe, L. S., \& Meengs, J. S. (2006). Reductions in portion size and energy density of foods are additive and lead to sustained decreases in energy intake. The American Journal of Clinical Nutrition, 83(1), 11-17.

Rolls, B. J., Roe, L. S., \& Meengs, J. S. (2007). The effect of large portion sizes on energy intake is sustained for 11 days. Obesity, 15(6), 1535-1543.

Ronda, G., Van Assema, P., \& Brug, J. (2001). Stages of change, psychological factors and awareness of physical activity levels in The Netherlands. Health Promotion International, 16(4), 305-314.

Steenhuis, I. H., Leeuwis, F. H., \& Vermeer, W. M. (2010). Small, medium, large or supersize. Trends in food portion sizes in The Netherlands. Public Health Nutrition, 13(6), 852-857.

Sutton, S. (1994). The past predicts the future. Interpreting behaviour-behaviour relationships in social psychological models of health behaviour. In D. R. Rutler \& L. Quine (Eds.), Social psychology and health. European perspectives. Aldershot: Avebury.

Swinburn, B. A., Caterson, I., Seidell, J. C., \& James, W. P. (2004). Diet, nutrition and the prevention of excess weight gain and obesity. Public Health Nutrition, 7 , 123-146.

Tabachnick, B. G., \& Fidell, L. S. (2001). Using multivariate statistics. Boston: Allyn and Bacon.

Trost, S. G., Owen, N., Bauman, A. E., Sallis, J. F., \& Brown, W. (2002). Correlates of adults' participation in physical activity. Review and update. Medicine E' Science in Sports \& Exercise, 34(12), 1996-2001.

van Rossum, C., Fransen, H., Verkaik-Kloosterman, J., Buurma-Rethans, E., \& Ocké, M. (2011). Dutch National Food Consumption Survey 2007-2010. Diet of children and adults aged 7 to 69 years. Bilthoven: National Institute for Public Health and the Environment.

van Sluijs, E. M., Griffin, S. J., \& van Poppel, M. N. (2007). A cross-sectional study of awareness of physical activity. Associations with personal, behavioral and psychosocial factors. International Journal of Behavioral Nutrition and Physical Activity, 4(1), 53.

Van Assema, P., Brug, J., Ronda, G., \& Steenhuis, I. (2001). The relative validity of a short Dutch questionnaire as a means to categorize adults and adolescents to total and saturated fat intake. Journal of Human Nutrition and Dietetics, 14(5), 377-390.

Van den Brink, C., \& Savelkoul, M. (2013). Gezondheidsmonitor GGD'en, CBS en RIVM. Bilthoven: National Institute for Public Health and the Environment.

Verweij, A. (2013). Onderwijsdeelname. Indeling opleidingsniveau. Bilthoven: National Institute for Public Health and the Environment.

Weinstein, N. D. (1988). The precaution adoption process. Health Psychology, 7(4), 355.

Weinstein, N. D., \& Lyon, J. E. (1999). Mindset, optimistic bias about personal risk and health-protective behaviour. British Journal of Health Psychology, 4(4), 289-300.

World Health Organization. (2013). Obesity and overweight. <http://www.who.int/ mediacentre/factsheets/fs311/en/>. Last accessed 14.06 . 